\title{
The Diagnosis and Treatment of Cholangiocarcinoma
}

\author{
Arndt Vogel, Henning Wege, Karel Caca, Björn Nashan, Ulf Neumann
}

\section{SUMMARY}

\begin{abstract}
Background: Cholangiocarcinoma (CCA) is the second most common primary hepatic tumor in Germany, with about 3500 new cases per year. In recent years, its prognosis has improved because of wider resections and the establishment of local treatment and chemotherapy in the palliative situation.
\end{abstract}

Methods: This review is based on pertinent articles that were retrieved by a selective literature search in the PubMed database with the keywords "cholangiocarcinoma AND diagnostic OR therapy." Articles in English or German published up to January 2014 were considered.

Results: The sole curative treatment for CCA is surgery, but $40-85 \%$ of all patients have recurrent disease even after radical excision. Because of this high recurrence rate, adjuvant treatments are now under intense discussion. For unresectable CCA without distant metastases, small case series have shown that liver transplantation can yield promising survival rates of over $50 \%$ at 5 years. For many patients with CCA, however, only palliative treatments can be offered, including endoscopic clearing of the biliary pathways. Because of the low prevalence of the disease, there have been only a few phase 3 studies of palliative chemotherapy for CCA. On the basis of one positive phase 3 study, chemotherapy with gemcitabine and cisplatin is considered the standard and now plays an established role in palliative care.

Conclusion: CCA presents a special challenge in gastroenterology, oncology, and visceral surgery because of the difficulty in establishing the diagnosis, local complications in the biliary pathways, and a high recurrence rate after resection. Future studies should address not only the role of adjuvant chemotherapy, but also the efficacy of combined local and systemic treatment.

\section{- Cite this as:}

Vogel A, Wege H, Caca K, Nashan B, Neumann U: The diagnosis and treatment of cholangiocarcinoma. Dtsch Arztebl Int 2014; 111: 748-54. DOI: 10.3238/arztebl.2014.0748

\footnotetext{
Department of Gastroenterology, Hepatology and Endocrinology, Hannover Medical School: Prof. Dr. med. Vogel

University Medical Center Hamburg-Eppendorf, I. Department of Internal Medicine, Hamburg: PD Dr. med. Wege

Department of Gastroenterology and Oncology, Klinikum Ludwigsburg: Prof. Dr. med. Caca University Medical Center Hamburg-Eppendorf, Department of Hepatobiliary and Transplant Surgery: Prof. Dr. med. Nashan, FACS, FRCSC, FEBS

Department of General, Visceral and Transplant Surgery, University Hospital RWTH Aachen: Prof. Dr. med. Neumann
}

C holangiocarcinoma (CCA) is an epithelial neoplasm that grows in the bile ducts and displays the histological characteristics of differentiation typical for cholangiocytes (1). In the ninth edition of its regular summaries of cancer in Germany, the Robert Koch Institute reported a total of 5300 newly diagnosed malignant tumors of the gallbladder and bile ducts in the year 2010 with a 5-year survival rate of 18 to $19 \%$ (overall total of new cancers: 477300 ). CCA is classified according to site into parenchymatous tumors (intrahepatic CCA [iCCA]), perihilar CCA (pCCA, Klatskin tumor), and distal CCA (dCCA) located in the bile ducts below the cystic duct $(2,3)$. Gallbladder carcinoma and papillary tumors are differentiated from CCA (Figure 1).

Epidemiological data show a steep rise in the incidence of CCA in the developed nations (4). In Germany, where the increase is attributed predominantly to demographic trends, most CCA occur sporadically after the age of 50 without any obvious risk factors. In Southeast Asia, the region of the world with the highest incidence of CCA, the principal risk factor is infestation of the bile ducts by liver flukes, e.g., Opisthorchis viverrini and Clonorchis sinensis. Chronic inflammations of the bile ducts, above all primary sclerosing cholangitis (PSC), are considered a risk factor for CCA in the western world. An estimated 5 to $10 \%$ of patients with PSC develop CCA at some time in the disease course, with an annual transformation rate of 0.5 to $1.5 \%(5,6)$. Other diseases identified in a case-control study as risk factors for iCCA, the incidence of which is increasing steeply in the developed nations, are chronic hepatitis $\mathrm{C}$, HIV infection, liver cirrhosis, diabetes mellitus, and chronic inflammatory bowel diseases (7). A recent meta-analysis confirmed smoking as a relevant risk factor for extrahepatic CCA (relative risk 1.23 compared with non-smokers) (8).

\section{Diagnosis}

While iCCA manifests itself primarily by local symptoms or metastases, clinical experience shows that the first sign of pCCA or dCCA is usually painless jaundice. Cholangitis requiring immediate drainage is present in only $10 \%$ of patients at first presentation (9). For this reason endoscopy should be preceded by staging by means of cross-sectional imaging. The best noninvasive method for spatial representation of the 
bile ducts is currently magnetic resonance cholangiopancreatography (MRCP), whose sensitivity and specificity match those of diagnostic endoscopic retrograde cholangiography (ERC) and percutaneous transhepatic cholangiography (PTC) (Figure 2). Magnetic resonance imaging (MRI) with MRCP enables assessment of local resectability and at the same time serves as a "route planner" for endoscopic drainage (10). Computed tomography (CT) shows good sensitivity for tumor infiltration of arteries and veins (11). It is particularly important to take full advantage of the locally available imaging modalities before planned resection of CCA, in order to establish the anatomical circumstances and the tumor burden. In the case of extrahepatic CCA, imaging also serves to ascertain the tumor type according to Bismuth and Corlette and thus the tumor site in relation to the confluence of the right and left hepatic ducts. Particularly with pCCA, however, neither the Bismuth-Corlette system nor the frequently used TNM classification suffices to indicate the appropriate treatment or predict the prognosis. The MSKCC and ICG classifications, based on resectability criteria, are more elaborate but possess much greater predictive value (e1, e2).

Histological confirmation of malignancy in iCCA is obtained primarily by percutaneous biopsy, while ERC can be used for potentially resectable pCCA and dCCA. Benign stenoses should be ruled out by ERC if at all possible. However, the sensitivity does not exceed $70 \%$ despite specificity of almost $100 \%$, so if cytology is negative, imaging suggests $\mathrm{CCA}$, and resectability seems likely, surgical exploration is often indicated. Sensitivity might be improved by means of molecular biology methods or direct biopsy via cholangioscopy (12), but these techniques are neither widely available nor have they been conclusively evaluated.

Determination of carbohydrate antigen 19-9 (CA19-9) can help to diagnose CCA in some patients. However, the sensitivity and specificity of this method are only 40 to $70 \%$, or 50 to $80 \%$, respectively, in

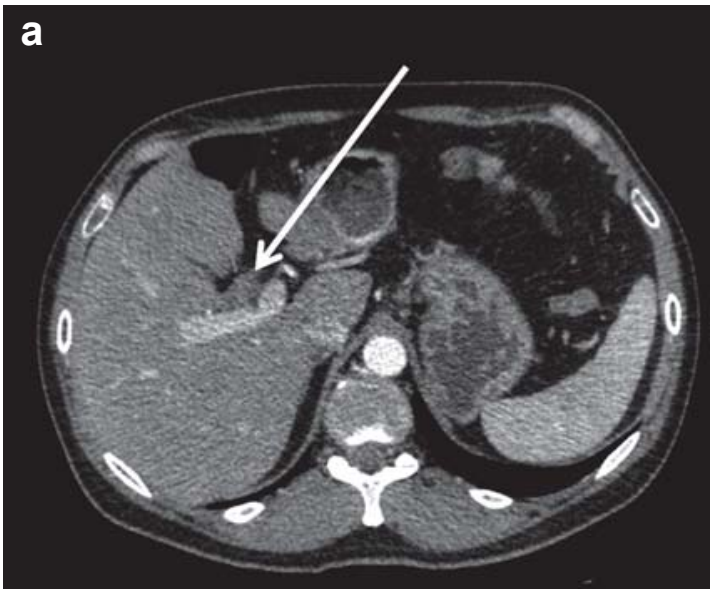

\section{FIGURE 1}

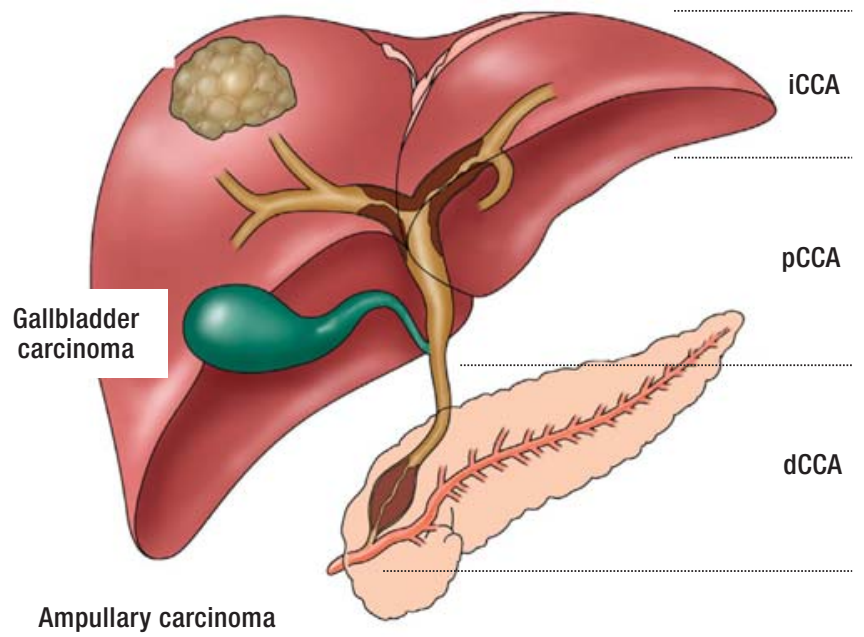

Classification and growth forms of cholangiocarcinoma (CCA).

CCA is divided into intrahepatic, perihilar, and distal carcinomas. Gallbladder carcinomas and periampullary carcinomas are classified separately.

iCCA. Furthermore, CA19-9 may be elevated in benign diseases such as cholangitis or choledocholithiasis with cholestasis and in other malignant tumors of the gastrointestinal tract. Levels above $1000 \mathrm{U} / \mathrm{L}$ are found particularly in patients with metastases (13). In the future these serum tests may be joined by proteome analyses from samples of bile or urine (14).

\section{Endoscopic treatment}

The role of preoperative and palliative endoscopic treatment has been investigated in a number of prospective studies and retrospective cohort studies. In resectable

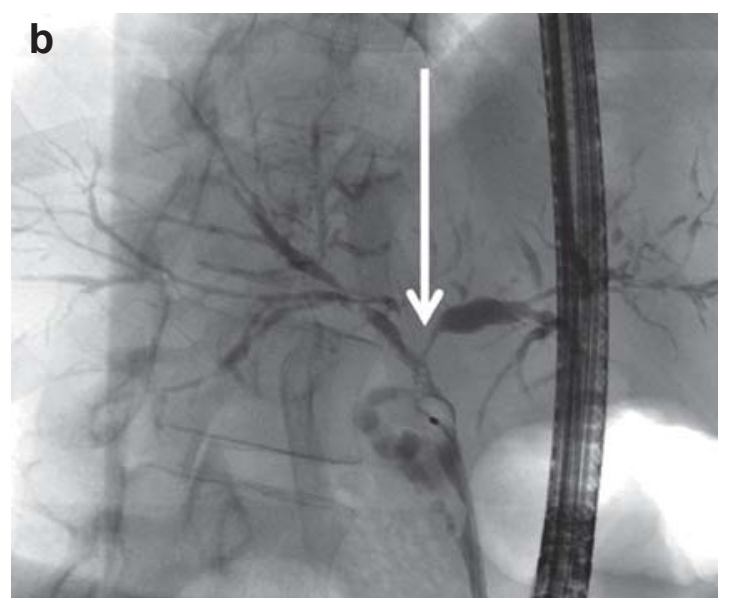

Figure 2:

Diagnosis of cholangiocarcinoma (CCA).

a) Perihilar cholangiocarcinoma (pCCA) manifesting on CT as thickening of wall of common hepatic duct b) Diagnosis of pCCA by means of ERCP with brush and forceps biopsy (modified from [1]) 
TABLE

RO resection rate and 5-year survival rate after surgical resection of perihilar cholangiocarcinoma (pCCA = Klatskin tumor)

\begin{tabular}{|c|c|c|c|c|}
\hline & \multicolumn{2}{|c|}{ Hilar resection alone } & \multicolumn{2}{|c|}{ Additional liver resection } \\
\hline & $\mathrm{n}(\mathrm{R} 0)$ & $\begin{array}{l}\text { 5-year } \\
\text { survival }\end{array}$ & $\mathrm{n}(\mathrm{R} 0)$ & $\begin{array}{l}\text { 5-year } \\
\text { survival }\end{array}$ \\
\hline $\begin{array}{l}\text { Miyazaki et al. } 1998 \\
(\mathrm{e} 6)\end{array}$ & $11(45 \%)$ & $0 \%$ & $15(-)$ & $10 \%$ \\
\hline $\begin{array}{l}\text { Lillemoe et al. } 2000 \\
\text { (e7) }\end{array}$ & $94(-)$ & $11 \%$ & $53(-)$ & $24 \%$ \\
\hline $\begin{array}{l}\text { Tabata et al. } 2000 \\
\text { (e8) }\end{array}$ & $22(-)$ & $20 \%$ & $53(-)$ & $10 \%$ \\
\hline $\begin{array}{l}\text { Gazzaniga et al. } 2000 \\
\text { (e9) }\end{array}$ & $20(-)$ & $0 \%$ & $17(-)$ & $25 \%$ \\
\hline $\begin{array}{l}\text { Lee et al. } 2000 \\
\text { (e10) }\end{array}$ & $17(24 \%)$ & $0 \%$ & $111(77 \%)$ & $24 \%$ \\
\hline $\begin{array}{l}\text { Nimura et al. } 2000 \\
\text { (e11) }\end{array}$ & $14(57 \%)$ & $16 \%$ & $128(78 \%)$ & $26 \%$ \\
\hline $\begin{array}{l}\text { Lee et al. } 2010 \\
\text { (e12) }\end{array}$ & $9(26 \%)$ & $17 \%$ & $205(77 \%)$ & $36 \%$ \\
\hline $\begin{array}{l}\text { de Jong et al. } 2012 \\
\text { (e13) }\end{array}$ & $48(54 \%)$ & $14 \%$ & $149(66 \%)$ & $25 \%$ \\
\hline $\begin{array}{l}\text { Song et al. } 2013 \\
(\mathrm{e} 14)\end{array}$ & $-(68 \%)$ & $0 \%$ & $-(76 \%)$ & $33 \%$ \\
\hline
\end{tabular}

CCA, preoperative bile duct drainage is not always necessary and is sometimes associated with an increased incidence of cholangitis (15). In the presence of acute cholangitis, bilirubin $>10 \mathrm{mg} / \mathrm{dL}$, or extensive hepatic resection, however, bile duct drainage with a plastic stent should be carried out to promote postoperative liver function and improve regeneration of the organ (16). The stent should be inserted preoperatively and should preferably drain only those segments of the liver that will remain after surgery.

Decompression of obstructed bile ducts is an important palliative intervention in patients with nonresectable tumors. Endoscopic drainage by means of ERC with stent implantation should be viewed as the standard procedure, because it achieves an effect comparable to that of percutaneous stent implantation or biliodigestive anastomosis with far fewer complications and a shorter stay in hospital (e3, e4). Whether unilateral or bilateral drainage is preferable is still being debated. A prospective randomized study showed no significant advantage of bilateral stenting, but $>30 \%$ of the hepatic tissues and all contrast-enhanced bile ducts should be drained (17). In dCCA metal stents are superior to plastic devices because they remain patent longer (18). In the short term metal stents are also superior to plastic stents in pCCA, because of the lower risk of occlusion and lower reintervention rate (19). In the long term, the lack of removability sometimes poses considerable problems if the drainage becomes ineffective owing to tumor invasion or overgrowth and revision is necessary. Ultimately the clinical situation, the locally available expertise, and the patient's preference determine the type of biliary drainage in the individual case.

Photodynamic therapy (PDT) can be used to optimize biliary drainage. Following injection of a photosensitizing agent, laser stimulation of optical fibers inserted by means of ERC achieves targeted tumor destruction in the bile ducts. A recently published meta-analysis of six prospective trials (albeit with only about 170 patients per arm and only two of the studies randomized) confirmed the findings of an initial small German randomized study in showing significant improvements in biliary efflux, quality of life, and life expectancy in comparison with stenting alone $(20,21)$. A recent Asian study revealed that patients who received additional systemic chemotherapy survived significantly longer than patients treated only with PDT (17 months versus 8 months, $p=0.005$ ) (22). Similar results have emerged from the Photostent 02 study, so far published only in the form of an abstract (ESMO 2010, abstract 8020; e5). The role of PDT in relation to the established chemotherapy needs to be investigated in prospective randomized trials. The ongoing international randomized phase III Pinnacle PHO1201 trial is investigating the combination of PDT with gemcitabine/cisplatin

A procedure for local ablation of bile duct tumors using a radiofrequency ablation catheter inserted by means of transpapillary ERC is also undergoing clinical testing (23). Other local treatments such as selective internal radiotherapy (SIRT), transarterial chemoembolization (TACE), and afterloading/brachytherapy can be integrated into the management of CCA in individual cases. Prospective randomized clinical trials will be required to assess the value of these treatment procedures, particularly in combination with systemic measures.

\section{Surgical treatment and liver transplantation}

Complete surgical resection is the sole potentially curative treatment option for CCA. No randomized trials of other treatment procedures have been published. Curative surgery should always be attempted when complete (R0) resection is judged possible. Distant metastases represent a contraindication. $\mathrm{R} 0$ resection is the most important factor for a successful outcome of surgery. The 5-year survival rate after R0 resection ranges from 0 to $40 \%(2,24,25)$. Further prognostic factors are lymph node involvement, vascular invasion, and tumor grade. Tumor infiltration of the perineural sheaths often cannot be reliably excluded on intraoperative frozen sections, so the safety margin should be as large as possible. Particularly in the case of pCCA, it is not uncommon to have to resect part of the portal vein or the hepatic artery in the vicinity of the tumor (26). In contrast to iCCA, surgical treatment of pCCA always requires complete removal of the 

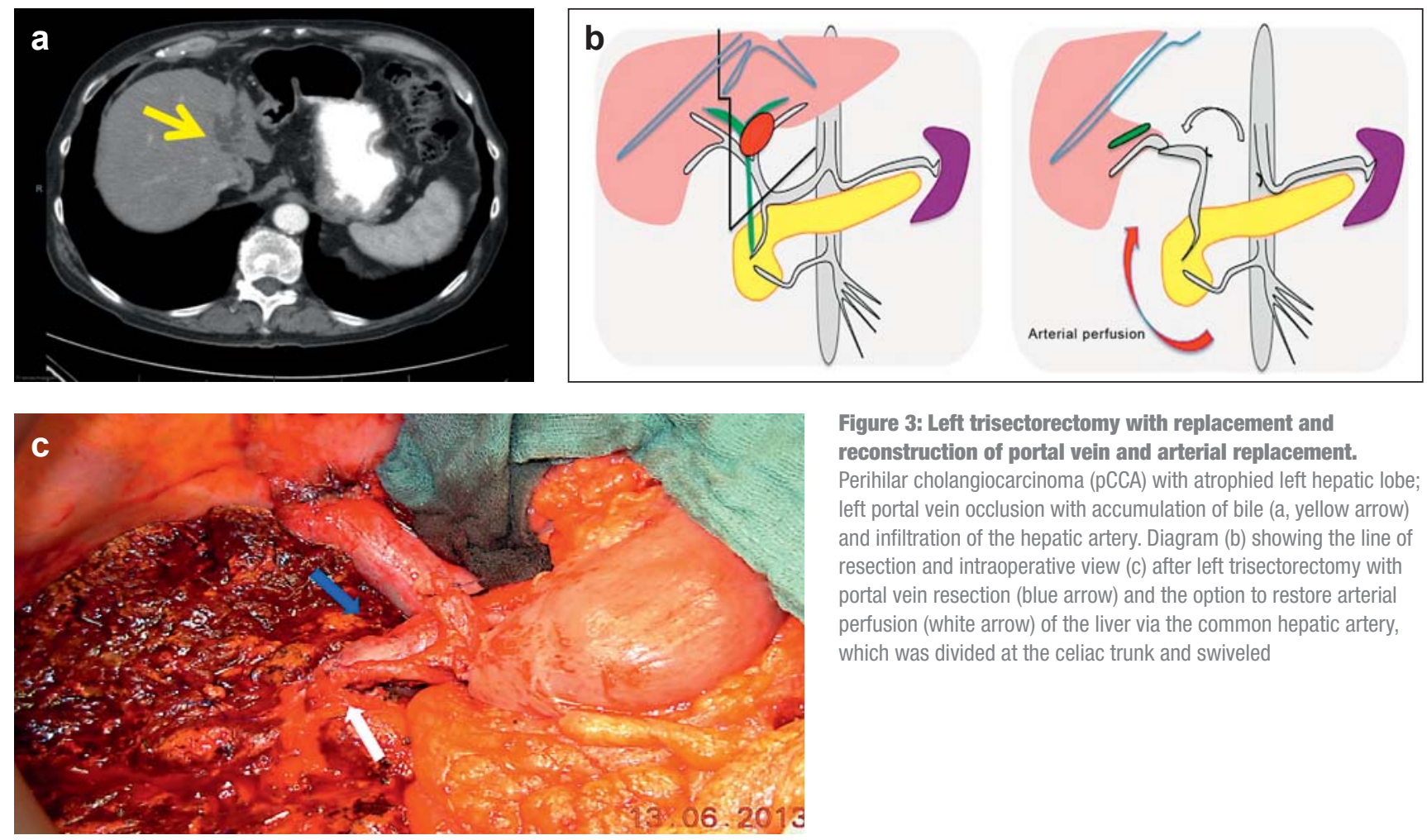

Figure 3: Left trisectorectomy with replacement and reconstruction of portal vein and arterial replacement. Perihilar cholangiocarcinoma ( $\mathrm{pCCA}$ ) with atrophied left hepatic lobe; left portal vein occlusion with accumulation of bile (a, yellow arrow) and infiltration of the hepatic artery. Diagram (b) showing the line of resection and intraoperative view (c) after left trisectorectomy with portal vein resection (blue arrow) and the option to restore arterial perfusion (white arrow) of the liver via the common hepatic artery, which was divided at the celiac trunk and swiveled

extrahepatic bile ducts with lymphadenectomy, followed by biliodigestive anastomosis with several ostia in the region of the intrahepatic margin of resection of the bile ducts (26). The combination of liver resection and bile duct resection yields a better oncological result than bile duct resection alone (Table). For tumors of the central section of the common bile duct, additional resection of the head of the pancreas may be necessary. Combined pancreatic head resection and hemihepatectomy is oncologically beneficial but can only be carried out in selected patients owing to the high perioperative mortality (27). Partial resection and reconstruction of the hilar vessels represents one of the crucial challenges of this procedure: besides partial resection of the tumor-adjacent portal vein bifurcation, partial resection and reconstruction of the hepatic artery is not only technically feasible but also associated with a comparable risk of morbidity (41 to $47 \%)(28,29)$.

The surgery carried out ranges from atypical segmentectomy or segment-oriented resection to hemihepatectomy (left or right) or extended resections (trisectorectomy) and complete lymphadenectomy (Figure 3). In the case of a predominantly right-sided tumor and planned extended right hemihepatectomy in the presence of a relatively small left hepatic lobe, for example, preoperative radiological embolization of the right branch of the portal vein may be performed to induce left-sided hypertrophy. A recently introduced two-stage procedure is the in-situ split technique with division of the portal vein. This procedure for management of iCCA, known as associating liver partition and portal vein ligation for staged hepatectomy (ALPPS), can be used to induce hypertrophy in the event of insufficient residual liver volume (30). Rapid hypertrophy may reduce the risk of tumor progress compared with conventional portal vein embolization (30). To date no studies comparing the procedures have been published. Resection of iCCA can also be combined with interventional procedures such as radiotherapy or thermic destruction of small lesions.

Surgery of pCCA has taken particularly great strides forward in the past 15 years, and specialized centers now achieve 5-year survival rates of 40 to $50 \%$ in selected patients (26). A multimodal treatment approach is vital for a successful outcome: long-term cure can only be achieved by extended partial hepatic resection, often with vascular replacement. Local resection of the bile duct without partial resection of the liver is seldom radical and is associated with significantly poorer survival.

Despite the advances in surgical techniques, a certain proportion of pCCA remain unresectable for anatomical or functional reasons. Liver transplantation (LTX) may represent an option for patients with lymphnode-negative tumors. On the basis of the impressive data from the USA (31), where there was a 5-year 
survival rate of $>50 \%$ after careful patient selection and neoadjuvant radiochemotherapy, this indication is currently being investigated in the Eurotransplant region of Europe, in the framework of the multicenter ProDuct Study (Feasibility and Efficacy of Adjuvant Chemotherapy after Liver Transplantation for Proximal Bile Duct Cancer, EudraCT no. 2010-020480-21). ProDuct is a pilot study to find out whether LTX of Klatskin tumors with adjuvant gemcitabine, preceded by application of a rigorous evaluation and staging algorithm before listing for LTX, attains survival rates comparable with other indications.

\section{Neoadjuvant and adjuvant treatment}

Up to $85 \%$ of patients suffer a recurrence within 3 years of CCA resection $(32,33)$. Adjuvant treatment strategies - radiotherapy, chemotherapy, or combined treatment - are thus being keenly debated. No highevidence-level studies showing success of adjuvant treatment have yet appeared. In a multicenter, prospective, randomized trial published as early as 2002 , 118 patients with CCA were treated by complete resection together with administration of mitomycin $\mathrm{C}$ and 5-fluorouracil versus resection alone, with no significant differences in 5-year survival rate or recurrencefree survival (32). The role of adjuvant radiotherapy is also not yet clearly defined. A prospective study showed no advantage of postoperative radiotherapy in extrahepatic CCA (34). The same conclusion was reached by a retrospective study of 1491 patients with extrahepatic CCA from the Surveillance, Epidemiology, and End Results (SEER) program, 473 of whom received adjuvant irradiation (35). A recent systematic review and meta-analysis on adjuvant treatment of CCA embracing a total of 6712 patients $(n=4915$ resection alone, $\mathrm{n}=1797$ resection and adjuvant treatment) also revealed no significant advantage of adjuvant treatment (36). There was a trend towards an advantage of chemotherapy over radiochemotherapy or radiotherapy, with nonsignificant differences in median overall survival. A further subanalysis showed a survival advantage of adjuvant treatment in patients with confirmed lymphogenic metastases and after R1 resection, so adjuvant treatment could be beneficial for patients at high risk of progressive tumor disease (N1, $\mathrm{R} 1$, or both); this should be investigated in a prospective randomized study. In this context, 20 university centers in Germany are carrying out the two-armed, controlled, randomized ACTICCA-1 study (Adjuvant Chemotherapy with Gemcitabine and Cisplatin Compared to Observation after Curative Intent Resection of Cholangiocarcinoma, EudraCT no. 2012-005078-70). This phase III study has 140 patients in each arm and is comparing observation alone with gemcitabine/cisplatin after macroscopically complete resection (contact: acticca@uke.de).

Individual cases of downstaging by preoperative systemic treatment have been described in case reports of patients with nonresectable tumors; here too, however, no conclusive studies have been published.

\section{Palliative treatment}

Monotherapy with gemcitabine was long considered standard for the palliative treatment of advanced CCA despite the absence of proof in a randomized phase III study. The average survival of patients treated with gemcitabine was around 6 months in several small phase II studies (37). Since the 2009 annual congress of the American Society of Clinical Oncology (ASCO) the combination of cisplatin and gemcitabine has been the standard treatment for patients in good general condition. Valle et al. showed that median survival could be improved significantly by intensification of treatment with gemcitabine and cisplatin compared with gemcitabine alone (11.7 months versus 8.1 months) (38). A meta-analysis of this study and a Japanese phase II study confirmed the significant improvement in overall survival of patients with CCA (39). The principal adverse effects of monotherapy or combination treatment were hematological, followed by fatigue and infections.

As is the case with other tumor entities, a number of new targeted agents such as monoclonal antibodies and "small molecules" are being investigated in various studies. To date none of these substances are licensed for the treatment of CCA.

There is currently no clear evidence regarding the use of second-line treatment, and no randomized studies have been published. Several retrospective analyses show better survival than with purely supportive treatment, with median survival of 7.5 months from the commencement of second-line treatment (40). In that case it seems practicable to switch to well tolerated substances that have not been used previously, e.g., 5-FU-based treatment after initial standard firstline treatment with gemcitabine and cisplatin.

\section{KEY MESSAGES}

- Cholangiocarcinoma (CCA) is the second most frequently occurring primary tumor of the liver in Germany, after hepatocellular carcinoma, and its incidence is increasing.

- Complete surgical resection is the only potentially curative treatment for CCA, but recurrences are frequent despite radical resection. Patients should be referred to specialized centers for discussion of surgical treatment options.

- The benefit of adjuvant chemotherapy has not yet been confirmed and is currently being investigated in Germany in the framework of the ACTICCA-1 study.

- Endoscopic biliary drainage by means of ERC is an integral component of the treatment of CCA.

- The evidence-based standard for palliative treatment of CCA is chemotherapy with gemcitabine and cisplatin. 


\section{Conflict of interest statement}

Prof. Vogel has received lecture fees from Dr. Falk Pharma

and Bayer HealthCare.

PD Dr. Wege has received lecture and consulting fees from Bayer HealthCare.

Prof. Caca has received lecture fees from Dr. Falk Pharma and Gore and study support (third-party funding) from Gore and Biolitec.

Prof. Nashan and Prof. Neumann declare that no conflict of interest exists.

Manuscript received on 9 April 2014, revised version accepted on 5 August 2014

Translated from the original German by David Roseveare.

\section{REFERENCES}

1. Rizvi S, Gores GJ: Pathogenesis, diagnosis, and management of cholangiocarcinoma. Gastroenterology 2013; 145: 1215-29.

2. DeOliveira ML, Cunningham SC, Cameron JL, et al.: Cholangiocarcinoma: thirty-one-year experience with 564 patients at a single institution. Ann Surg 2007; 245: 755-62.

3. Witzigmann H, Wiedmann M, Wittekind C, Mossner J, Hauss J: Therapeutical concepts and results for Klatskin tumors. Dtsch Arztebl Int 2008; 105: 156-61.

4. Blechacz B, Gores GJ: Cholangiocarcinoma: advances in pathogenesis, diagnosis, and treatment. Hepatology 2008; 48: 308-21.

5. Razumilava N, Gores GJ: Classification, diagnosis, and management of cholangiocarcinoma. Clin Gastroenterol Hepatol 2013; 11: 13-21 e1; quiz e3-4.

6. Lutz H, Trautwein C, Tischendorf JW: Primary sclerosing cholangitis: diagnosis and treatment. Dtsch Arztebl int 2013; 110 867-74.

7. Shaib YH, El-Serag HB, Davila JA, Morgan R, McGlynn KA: Risk factors of intrahepatic cholangiocarcinoma in the United States: a case-control study. Gastroenterology 2005; 128: 620-6.

8. Ye XH, Huai JP, Ding J, Chen YP, Sun XC: Smoking, alcohol consumption, and the risk of extrahepatic cholangiocarcinoma: A meta-analysis. World J Gastroenterol 2013; 19: 8780-8.

9. Blechacz BR, Gores GJ: Cholangiocarcinoma. Clin Liver Dis 2008; 12: 131-50, ix

10. Park HS, Lee JM, Choi JY, et al.: Preoperative evaluation of bile duct cancer: MRI combined with MR cholangiopancreatography versus MDCT with direct cholangiography. Am J Roentgeno 2008; 190: 396-405

11. Ruys AT, van Beem BE, Engelbrecht MR, Bipat S, Stoker J, van Gulik TM: Radiological staging in patients with hilar cholangiocarcinoma: a systematic review and meta-analysis. Br J Radiol 2012; 85: 1255-62.

12. Charatcharoenwitthaya $P$, Enders FB, Halling KC, Lindor KD: Utility of serum tumor markers, imaging, and biliary cytology for detecting cholangiocarcinoma in primary sclerosing cholangitis. Hepatology 2008; 48: 1106-17.

13. Patel AH, Harnois DM, Klee GG, LaRusso NF, Gores GJ: The utility of CA 19-9 in the diagnoses of cholangiocarcinoma in patients without primary sclerosing cholangitis. Am J Gastroenterol 2000; 95: 204-7.

14. Metzger J, Negm AA, Plentz RR, et al.: Urine proteomic analysis differentiates cholangiocarcinoma from primary sclerosing cholangitis and other benign biliary disorders. Gut 2013; 62: 122-30.

15. Hochwald SN, Burke EC, Jarnagin WR, Fong Y, Blumgart LH: Association of preoperative biliary stenting with increased postoperative infectious complications in proximal cholangiocarcinoma. Arch Surg 1999; 134: 261-6.

16. Iacono C, Ruzzenente A, Campagnaro T, Bortolasi L, Valdegamberi A, Guglielmi A: Role of preoperative biliary drainage in jaundiced patients who are candidates for pancreatoduodenectomy or hepatic resection: highlights and drawbacks. Ann Surg 2013; 257: 191-204.
17. de Palma GD, Galloro G, Siciliano S, Iovino P, Catanzano C: Unilateral versus bilateral endoscopic hepatic duct drainage in patients with malignant hilar biliary obstruction: results of a prospective, randomized, and controlled study. Gastrointest Endosc 2001; 53: 547-53.

18. Soderlund C, Linder S: Covered metal versus plastic stents for malignant common bile duct stenosis: a prospective, randomized, controlled trial. Gastrointest Endosc 2006; 63: 986-95.

19. Mukai T, Yasuda I, Nakashima M, et al.: Metallic stents are more efficacious than plastic stents in unresectable malignant hilar biliary strictures: a randomized controlled trial. J Hepatobiliary Pancreat Sci2013; 20: 214-22.

20. Leggett CL, Gorospe EC, Murad MH, Montori VM, Baron TH, Wang KK: Photodynamic therapy for unresectable cholangiocarcinoma: a comparative effectiveness systematic review and meta-analyses. Photodiagnosis Photodyn Ther 2012; 9: 189-95.

21. Ortner ME, Caca K, Berr F, et al.: Successful photodynamic therapy for nonresectable cholangiocarcinoma: a randomized prospective study. Gastroenterology 2003; 125: 1355-63.

22. Park DH, Lee SS, Park SE, et al.: Randomised phase II trial of photodynamic therapy plus oral fluoropyrimidine, S-1, versus photodynamic therapy alone for unresectable hilar cholangiocarcinoma. Eur J Cancer 2014, 50: 1259-68.

23. Tal A0, Vermehren J, Friedrich-Rust M, et al.: Intraducta endoscopic radiofrequency ablation for the treatment of hilar non-resectable malignant bile duct obstruction. World $\mathrm{J}$ Gastrointest Endosc2014; 6: 13-9.

24. Ramacciato G, Nigri G, Bellagamba R, et al.: Univariate and multivariate analysis of prognostic factors in the surgical treatment of hilar cholangiocarcinoma. American Surg 2010; 76: 1260-8.

25. Nuzzo G, Giuliante F, Ardito F, et al.: Intrahepatic cholangiocarcinoma: prognostic factors after liver resection. Updates Surg 2010; 62: 11-9

26. Seehofer D, Kamphues C, Neuhaus P: Resektion von KlatskinTumoren. Chirurg 2012; 83: 221-8.

27. Hemming AW, Magliocca JF, Fujita S, et al.: Combined resection of the liver and pancreas for malignancy. Journal of the American College of Surgeons 2010; 210: 808-14.

28. Shimizu H, Kimura F, Yoshidome H, et al.: Aggressive surgical resection for hilar cholangiocarcinoma of the left-side predominance: radicality and safety of left-sided hepatectomy. Ann Surg 2010; 251: 281-6.

29. Nagino M, Nimura Y, Nishio $H$, et al.: Hepatectomy with simultaneous resection of the portal vein and hepatic artery for advanced perihilar cholangiocarcinoma: an audit of 50 consecutive cases. Ann Surg 2010; 252: 115-23.

30. Schnitzbauer AA, Lang SA, Goessmann $H$, et al.: Right portal vein ligation combined with in situ splitting induces rapid left lateral liver lobe hypertrophy enabling 2-staged extended right hepatic resection in small-for-size settings. Ann Surg 2012; 255: 405-14.

31. Darwish Murad S, Kim WR, Harnois DM, et al.: Efficacy of neoadjuvant chemoradiation, followed by liver transplantation, for perihilar cholangiocarcinoma at 12 US centers. Gastroenterology 2012; 143: 88-98 e3; quiz e14.

32. Takada $\mathrm{T}$, Amano $\mathrm{H}$, Yasuda $\mathrm{H}$, et al.: Is postoperative adjuvant chemotherapy useful for gallbladder carcinoma? A phase III multicenter prospective randomized controlled trial in patients with resected pancreaticobiliary carcinoma. Cancer 2002; 95 : 1685-95.

33. Tamandl D, Herberger B, Gruenberger B, Puhalla $H$, Klinger M, Gruenberger $\mathrm{T}$ : Influence of hepatic resection margin on recurrence and survival in intrahepatic cholangiocarcinoma. Ann Surg Oncol 2008; 15: 2787-94.

34. Pitt HA, Nakeeb A, Abrams RA, et al.: Perihilar cholangiocarcinoma. Postoperative radiotherapy does not improve survival. Ann Surg 1995; 221: 788-97; discussion 97-8. 
35. Vern-Gross TZ, Shivnani AT, Chen K, et al.: Survival outcomes in resected extrahepatic cholangiocarcinoma: effect of adjuvant radiotherapy in a surveillance, epidemiology, and end results analysis. Int J Radiat Oncol Biol Phys 2011; 81: 189-98.

36. Horgan AM, Amir E, Walter T, Knox JJ: Adjuvant therapy in the treatment of biliary tract cancer: a systematic review and meta-analysis. J Clin Oncol 2012; 30: 1934-40.

37. Eckel F, Schmid RM: Chemotherapy in advanced biliary tract carcinoma: a pooled analysis of clinical trials. $\mathrm{Br} \mathrm{J}$ Cancer 2007; 96: 896-902.

38. Valle J, Wasan $\mathrm{H}$, Palmer DH, et al.: Cisplatin plus gemcitabine versus gemcitabine for biliary tract cancer. N Engl J Med 2010; 362: 1273-81

39. Valle JW, Furuse J, Jitlal M, et al.: Cisplatin and gemcitabine for advanced biliary tract cancer: a meta-analysis of two randomised trials. Ann Oncol 2014; 25: 391-8.
40. Walter T, Horgan AM, McNamara M, et al.: Feasibility and benefits of second-line chemotherapy in advanced biliary tract cancer: a large retrospective study. Eur J Cancer 2013; 49: 329-35.

\section{Correspondinf author}

Prof. Dr. med. Arndt Voge

Klinik für Gastroenterologie, Hepatologie und Endokrinologie

Medizinische Hochschule Hannover

Carl-Neuberg-Str. 1

30625 Hannover, Germany

vogel.arndt@mh-hannover.de

Q For eReferences please refer to: www.aerzteblatt-international.de/ref4414 


\title{
REVIEW ARTICLE
}

\section{The Diagnosis and Treatment of Cholangiocarcinoma}

\author{
Arndt Vogel, Henning Wege, Karel Caca, Björn Nashan, Ulf Neumann
}

\section{eREFERENCES}

e1. Zaydfudim VM, Clark CJ, Kendrick ML, et al.: Correlation of staging systems to survival in patients with resected hilar cholangiocarcinoma. Am J Surg 2013; 206: 159-65.

e2. Deoliveira ML, Schulick RD, Nimura Y, et al.: New staging system and a registry for perihilar cholangiocarcinoma. Hepatology 2011; 53: $1363-71$.

e3. Speer AG, Cotton PB, Russell RC, et al.: Randomised trial of endoscopic versus percutaneous stent insertion in malignant obstructive jaundice. Lancet 1987; 2: 57-62.

e4. Andersen JR, Sorensen SM, Kruse A, Rokkjaer M, Matzen P: Randomised trial of endoscopic endoprosthesis versus operative bypass in malignant obstructive jaundice. Gut 1989; 30: 1132-5.

e5. Pereira S, Hughes SK, Roughton M, et al.: Photostent-02; Porfimer sodium photodynamic therapy plus stenting versus stenting alone in patients (Pts) with advanced or metastatic cholangiocarcinomas and other biliary tract tumours (Btc): A multicentre, randomised phase III trial. Ann Oncol 2010; 21: 250.

e6. Miyazaki M, Ito H, Nakagawa K, et al.: Aggressive surgical approaches to hilar cholangiocarcinoma: hepatic or local resection? Surgery 1998; 123: 131-6.

e7. Lillemoe KD, Cameron JL: Surgery for hilar cholangiocarcinoma: the Johns Hopkins approach. J Hepatobiliary Pancreat Surg 2000; $7: 115-21$. e8. Tabata M, Kawarada Y, Yokoi H, Higashiguchi T, Isaji S: Surgical treatment for hilar cholangiocarcinoma. J Hepatobiliary Pancreat Surg 2000; 7: 148-54.

e9. Gazzaniga GM, Filauro M, Bagarolo C, Mori L: Surgery for hilar cholangiocarcinoma: an Italian experience. J Hepatobiliary Pancreat Surg 2000; 7: 122-7

e10. Lee SG, Lee YJ, Park KM, Hwang S, Min PC: One hundred and eleven liver resections for hilar bile duct cancer. J Hepatobiliary Pancreat Surg 2000; 7: 135-41.

e11. Nimura Y, Kamiya J, Kondo S, et al.: Aggressive preoperative management and extended surgery for hilar cholangiocarcinoma: Nagoya experience. J Hepatobiliary Pancreat Surg 2000; 7 : $155-62$.

e12. Lee SG, Song GW, Hwang S, et al.: Surgical treatment of hilar cholangiocarcinoma in the new era: the Asan experience. J Hepatobiliary Pancreat Sci 2010; 17: 476-89.

e13. de Jong MC, Marques H, Clary BM, et al.: The impact of portal vein resection on outcomes for hilar cholangiocarcinoma. Cancer 2012; 118: 4737-47.

e14. Song SC, Choi DW, Kow AW, et al.: Surgical outcomes of 230 resected hilar cholangiocarcinoma in a single centre. ANZ J Surg2013; 83: 268-74. 